\title{
LOS PRINCIPIOS GENERALES DEL DERECHO $Y$ LOS PRINCIPIOS PARTICULARES DEL DERECHO LABORAL
}

\author{
Victor Ferro Delgado
}

\section{INTRODUCCION}

Las normas contenidas en el Título Preliminar del Código Civil expresan disposiciones de aplicación general en el Derecho y no así, únicamente, en el Derecho Civil. Representan, pues, una suerte de punto intermedio entre la Constitución y las demás disposiciones que contiene el ordenamiento jurídico del país, no obstante que, formalmente, no serían más que normas con rango de ley, susceptibles de ser modificadas por otra ley.

Empero, es claro que el alcance de sus disposiciones no puede constreñirse únicamente al campo civil: no podría admitirse que en otras ramas de la ciencia jurídica sí esté amparado el abuso del derecho, o que la salvaguarda al orden público o a las buenas costumbres se limita al ámbito civil, y no a todas las ramas del Derecho.

Por cierto, ello no surge de lo dispuesto en el artículo $9^{\circ}$ del Título Preliminar, que establece la supletoriedad de "las disposiciones del Código Civil a las relaciones y situaciones jurídicas reguladas por otras leyes, siempre que no sean incompatibles con su naturaleza". En rigor, dicha norma está referida a la totalidad de las disposiciones contenidas en el Código Civil, sin privilegiar especialmente a las que contempla el Título Preliminar. No obstante, es notorio que entre unas y otras disposiciones existe una distinta vocación de universalidad, lo que nos lleva a considerar que ello obedece a que, fundamentalmente, las normas del Título Preliminar son expresiones positivas de principios generales de derecho, válidos -en principios- para todos los derechos establecidos, o, como señala Rubio, porque el "alcance normativo (del Título Prelimi- 
nar) es mayor, abarcando al conjunto del sistema jurídico o, cuanto menos, a partes considerables de él, mediante el aporte de varios principios generales contenidos en sus normas" (1). Sin embargo, en cuanto a principios generales - antes que como normas imperativas respecto de la totalidad de las diversas ramas del Derecho- deben ser compulsados, o contrapuestos, con otros principios particulares de un sector específico del Derecho, a fin de determinar la forma como unos y otros interactúan o son re-elaborados aportando una solución particular.

Es este aspecto el que nos interesa destacar, analizando la norma contenida en el artículo $1^{\circ}$ del Título Preliminar-la ley se deroga por otra ley- que recoge el principio general de jerarquía de las normas, en relación con el principio protector, o pro-operario, del Derecho Laboral, en sus reglas "norma más favorable" y "condición más beneficiosa".

(1) Rubio Correa, Marcial. Para Leer el Código Civil. Lima, Fondo Editorial de la Pontificia Universidad Católica del Perú. 1986. p. 18. 


\section{CAPITULO I}

\section{LOS PRINCIPIOS GENERALES DEL DERECHO}

1. Aproximación. 2. Objeto. 3. Naturaleza Jurídica. 4. Su Identificación. 5. Principios Generales y Máximas Jurídicas.

\section{Aproximación}

La primera aproximación que debemos efectuar a los principios generales del Derecho, surge de la Octava Disposición del Título Preliminar:

"Los Jueces no pueden dejar de administrar justicia por defecto o deficiencia de la ley. En tales casos deben aplicar los principios generales del Derecho $\mathrm{y}$, preferentemente, los que inspiran el Derecho Peruano".

Si bien esta disposición tiene su antecedente en el artículo $23^{\circ}$ del Título Preliminar del Código Civil de 1936, la Constitución de 1979 , artículo $233^{\circ}$ en su inciso $6^{\circ}$, ya había establecido la norma que recoge el actual Título Preliminar.

La referencia, pues, a los principios generales del Derecho estaría, de primera intención, destinada a suplir las lagunas de la ley. Así, desde una perspectiva estrictamente positivista, implicaría que el intérprete que no encuentre en la normatividad vigente una disposición aplicable al caso concreto, estaría facultado a recurrir a los principios generales del derecho peruano, o del derecho en general. Por cierto, a diferencia del Derecho Español, nuestro Título Preliminar no enumera las fuentes del ordenamiento jurídico peruano, y por ende no existe referencia a la costumbre ni a los usos jurídicos. Empero, un sector de la doctrina estima que en un país 
pluricultural como el nuestro, la costumbre y la jurisprudencia deben tener reconocimiento de su carácter jurídico (2).

Pues bien, recurrir a los principios generales del derecho exige partir de una conceptualización de los mismos, lo que implica ingresar a uno de los temas de más difícil precisión en las problemática jurídica.

\section{Objeto}

De una primera reflexión, surgiría que los principios generales del Derecho tendrían importancia cuando se trate de suplir lagunas en el ordenamiento positivo, y que por ende, su valor estaría referido a una cuestión meramente interpretativa del Derecho arte el supuesto que no exista norma específica que aplicar. A esta posición se adscribe Albaladejo cuando sostiene que "con <los principios generales $>$ se llenan las lagunas o vacíos que existan en el derecho legisiado y consuetudinario (pues la ley y la costumbre no regulan, no prevén, todos los casos que pueden presentarse en la práctica, sino los mas corrientes e importantes), de forma que, como dichos principios generales completan a este derecho legislado y consuetudinario, llenando sus huecos, la totalidad jurídica -el ordenamiento jurídico civil- que en conjunto forman la ley, la costumbre y los principios generales, carece de lagunas, pues contiene normas para solucionar todos los casos posibles" (3).

Podrán existir principios positivos, vale decir aquellos que se acogen en el derecho positivo, pero también principios extrapositivos, que Albaladejo define como los principios jurídicos que recogen las leyes y las costumbres, o que puedan obtenerse de la concepción jurídica que en ellas se acepta (4).

Sin embargo, a esta concepción de los principios generales del

(2) Rubio Correa, Marcial. Ibidem. p. 142-143.

(3) Albaladejo, Manuel. Derecho Civil Introducción y Parte General. Barcelona, Librería Bosch, 1980. pp. 112-113.

(4) Ibidem. p. 114. 
derecho como integradores ante las lagunas que puede enfrentar el intérprete ante el caso concreto, cabe contraponer otra concepción:

"No es sólo la integración de las posibles lagunas de un tex to legal lo que obliga en muchas ocasiones a recurrir a criterios extralegales. También la determinación del verdadero alcance, sentido y significación que dentro del ordenamiento jurídico posee una determinada disposición legal, solamente puede hacerse, en ocasiones, acudiendo a tales criterios extralegales" (5).

Esta distinta concepción del objeto de los principios generales hace necesario, pues, analizar su real naturaleza jurídica.

\section{Naturaleza Juridica}

Para un sector de la doctrina, los principios generales del derecho son expresiones del derecho natural. Esta posición iusnaturalista se enfrenta a la corriente positivista, conforme a la cual cabe extraer de las disposiciones legales los principios generales del derecho que contienen, mediante abstracciones de su contenido. Diez Picazo y Antonio Bullón refutan ambas posiciones. Frente a la posición iusnaturalista señalan que, paralelamente a las reglas del derecho natural, existen otros principios y refieren, a modo de ejemplo, que en el ordenamiento de una sociedad de ideología liberal y en el de otra de ideologia marxista, las normas de sus instituciones serán distintas al serlos sus principios informadores. Tampoco estos autores comparten la posición positivista, ya que consideran que la generalización de principios generales a partir de normas positivas representaría únicamente un medio técnico para descubrir los principios inspiradores, pues podrán existir principios que aún no han agotado su potencialidad normativa por no haber tenido pleno desarrollo por lo que su plasmación legislativa sería aún incipiente.

(5) Diez Picazo, Luis y Bullón, Antonio. Sistema de Derecho Civil. Tercera Edición. Madrid. Editorial Tecnos. p. 176. 
En base a lo expuesto, concluyen Diez-Picazo y Gullón:

"Por todo ello, no se puede afirmar rotundamente que los principios generales se hallan fuera ni por el contrario, dentro del ordenamiento jurídico. Lo que sí resplandece en todo caso es su función vertebradora o estructuradora del mismo porque: $1^{\circ}$, tienen un carácter básico y fundamental en la organización del grupo humano que por él se conduce; $2^{\circ}$, revelan de modo espontáneo el sistema de creencias y convicciones en que reposa la organización de tal grupo social. Y ello porque si el derecho es una ordenación organizadora de la comunidad social, no hay que olvidar que reposa en un conjunto de creencias o de convicciones del grupo humano a que va destinado. ..".

Estas normas gozan de una característica especial: no se encuentran fundadas en la autoridad del Estado, como la ley, ni en los usos o prácticas de determinadas fuerzas o grupos sociales, como la costumbre. Tienen su fundamento en la comunidad entera, a través de sus convicciones y creencias, de forma que es aquella el auténtico poder creador de las normas de que tratamos"' (6).

En la línea de pensamiento expuesta, De Castro asigna tres funciones a los principios generales:

"1. Constituyen el fundamento de todo el ordenamiento jurídico. Son desde este punto de vista las bases últimas de todo el derecho positivo. Son ellos, los que convierten al ordenamiento jurídico de conjunto inorgánico en unidad vital.

“2. Los principios generales del derecho son normas orientadoras de la función interpretativa, en cuanto señalan los motivos y los criterios de interpretación de las demás normas, indicando las fórmulas interpretativas que se deben elegir. V.gr., una

(6) Ibidem. p. 180 . 
norma concorde con los principios generales del derecho deberá ser objeto de una interpretación extensiva y amplia mientras que, en cambio, cuando la norma concreta aparezca en contradicción con un principio general su interpretación deberá ser restrictiva.

"3. Los principios constituyen un sistema de integración de las lagunas de la ley. Cuando no existe ley aplicable a un punto controvertido y no existe tampoco norma consuetudinaria que permite resolverlo, debe el Juez decidir de acuerdo con los principios generales del Derecho" (7).

Creemos que es dentro de esa línea de pensamiento que debemos conceptuar el verdadero alcance de los principios generales, antes que el de una mera función de suplencia ante las lagunas que pueden existir en la legislación, $o$ inclusive en la jurisprudencia o la costumbre. Así, el objeto de los principios generales del Derecho dependerá de la naturaleza que les asignemos, siendo nuestra opción por considerar que su rol esencial es el de vertebrar el ordenamiento jurídico a través de las convicciones de una comunidad social dándole así coherencia y sentido a sus normas.

\section{Identificación de los Principios Generales del Derecho}

Una vez enunciados los conceptos que ya hemos precisado, debemos detenernos en considerar a quien corresponde la determinación de los principios generales del derecho, esto es, la competencia para su identificación. Betti refiere el problema en los siguientes términos:

"Pero el punto delicado de la cuestión es ver en qué modo y por medio de qué órganos debe manifestarse la conciencia social de la época, conciencia que -según cuanto se ha dicho- es naturalmente llamada a representarse las funciones de las relaciones de la vida, valorando en ellas las exigencias sociales, en cuanto postulan una disciplina jurídica a elaborar ulterior-

(7) De Castro. Citado por Diez Picazo. Ibidem. p. 183. 
mente. Pues bien, nosotros decimos, respondiendo a la pregunta propuesta que el órgano de la conciencia social en el cumplimiento de tal tarea debe hoy reconocerse en la jurisprudencia, entendida en el sentido más alto de jurisprudencia tanto teórica (ciencia jurídica) como práctica. La jurisprudencia así entendida es competente para identificar y elaborar aquellos principios generales de derecho que, ofreciendo directrices y criterio de valoración, no se agotan en simples normas particulares, constituyendo instrumentos indispensables de una interpretación integradora del orden jurídico que sobrepasa los confines de la analogía legis" (8).

Creemos, pues, que la conciencia jurídica de una colectividad surge no sólo de la re-creación del Derecho que puedan realizar los jueces mediante fallos jurisdiccionales - jurisprudencia en sentido estricto- sino de la propia ciencia jurídica. Ambas son las llamadas a erigirse en elementos fundamentales a este propósito, pero no excluyentemente de la tarea que corresponde a la propia legislación. Esta puede también recoger determinadas constantes que son plasmadas en distintas disposiciones que, de modo paulatino, van generando o expresando una conciencia juridica -en el amplio sentido del término-- hasta terminar por convertirse en principios generales de Derecho.

\section{Principios Generales y Máximas Juridicas}

Entre los principios de derecho y las máximas jurídicas existen diferencias avasalladoras. Como señala Villar:

"El principio general de derecho es esencialmente algo valorativo... (mientras que) el apotegma interpretativo es solamente un instrumento para integrar las lagunas legales y tienen una naturaleza pseudológica, y por tanto permanente. Dicho más simplemente, la analogía podrá haber sido objeto de diferentes teorías

(8) Betti Emilio. Interpretación de la Ley y los Actos Jurídicos. Madrid. 1975. Editoriales de Derecho Reunidas. p. 293. 
desde Aristóteles hasta hoy, pero en su esencia es la misma desde entonces hasta la actualidad. Un apotegma lógico podrá ser analizado cada vez más estrictamente, pasando incluso de ser un argumento tópico o falsamente lógico a ser un argumento de silogismo plenamente lógico.

Frente a ello el principio general de derecho no es estático ni permanente, responde a la ideología social y es la penetración de tal ideología, de los valores predominantes en la sociedad e incluso de los mitos aceptados en cada país y en cada momento en el ordenamiento jurídico. Es el punto de unión entre el consenso social, los valores predominantes y las aspiraciones de una sociedad con el sistema de derecho: de ahí que la propia ley les denomine principios generales informadores; en cuanto recogen tales valores tendrán efectividad que perderán de otra manera" (9).

Gráficamente, Diez-Picazo y Bullón, señalan que:

"Las reglas son refranes jurídicos o fórmulas concisas que comprenden una experiencia jurídica. No tienen valor jurídico propio y son simples recursos nemotécnicos o pedagógicos. No forman por sí mismas parte del ordenamiento jurídico sino de la ciencia del Derecho" (10);

Señala Villar, explicando la diferencia entre los principios generales y los apotegmas jurídicos, que los principios generales no son inmutables sino que por el contrario están en progresiva mutación toda vez que respecto del derecho se sitúan simultáneamente en el mundo ideal de los valores y en el mundo real entre los que existe una recíproca interrelación. El mundo inmutable de los va-

(9) Villar Palasi, José Luis. La Interpretación en los Apotegmas JurídicoLógicos. Madrid. Editorial Tecnos. pp. 130-131.

(10) Ob. cit. p. 184 
lores es filtrado por la ideología y el consenso en cada momento y en cada pais, y es precisamente lo que le da aceptación a esos valores. Considera Villar que son principios generales los que permiten sistematizar y valorar en sentido axiológico un determinado ordenamiento jurídico, dentro de la multiplicidad de sus normas haciéndolas inteligibles globalmente: "una máxima de Derecho es sólo la estela de lo que la ley ya ha decidido. Un principio general, por el contrario, es la proa de un rompehielos: afilada y apta para romper esa costra de inmovilidad del Derecho positivo" (11).

Sin embargo, los principios generales constituyen entre si un basamento interactuante que provocan, en sus variadas combinaciones, conflictos de prioridad en su aplicación e inclusive antagonismos o contradicciones entre los mismos, como resultado de que la sociedad suele admitir, simultáneamente valores contrapuestos entre sí.

(11) Ob. cit. p. 137. 


\section{CAPITULO II}

\section{LOS PRINCIPIOS DEL DERECHO DEL TRABAJO}

1. Concepto y Naturaleza Jurídica. 2. Principios Generales o Reglas de Interpretación. 3. Principio Protector. 4. Regla de la norma más favorable. 5 . Regla de la Condición más beneficiosa.

\section{Concepto y Naturaleza Juridica}

Manuel Alonso García conceptuó a los principios generales del derecho del trabajo como "aquellas líneas directrices o postulados básicos de la tarea interpretativa que inspiran el sentido con que han de aplicarse las normas laborales, ser desentrañado -en caso de duda- el contenido de las relaciones de trabajo, o desvelada justamente la intención que presidiera la voluntad de los sujetos contratantes" (12). Sin embargo, para este autor es menester que los principios generales del Derecho Laboral estén positivizados, vale decir expresados en normas legales de manera tal que aparezcan expresamente formulados:

"En cierto modo, pues, estos principios - que cabría entender, desde ciertos planos de consideración, como informadores del mismo Derecho del Trabajo en cuanto a ordenamiento total, y de sus normas y relaciones en concreto, en el orden de su aplicación- vienen a constituir el fundamento del sistema jurídicopositivo del trabajo, y no admiten contradicción posible con los preceptos legales, ya que, según hemos indicado, se hacen patentes a través de normas legales.

(12) Alonso García, Manuel. Curso de Derecho del Trabajo. Barcelona, Editorial Ariel, 1980. p. 251. 
Pero -repetimos-- la significación que, a nuestro juicio cabe aplicar a estos principios, con mayor eficacia, y ligada a su auténtico sentido, es la de actuar como orientadores de la labor interpretativa, indicando el método esclarecedor de las normas, y, en cada caso, la fórmula interpretativa que se debe elegir" (13).

Si bien no escapa al tratadista español el rol vertebrador de los principios del Derecho del Trabajo, sin embargo, cae en la concepción positivista -e inmovilizante- de pretender que los principios generales para ser tales deben estar debidamente concretados en normas legales. Ello ciertamente los priva de su función más enaltecedora: la de reflejar los consensos sociales de una colectividad que se traducen en convicciones jurídicas más allá de lo que el ordenamiento positivo haya podido recoger. Esta función dinámica, no es advertida por diversos tratadistas del Derecho del Trabajo, algunos tan ilustres como Mario de la Cueva, quien relativiza el rol de los principios generales. En efecto, al comentar la Constitución Mexicana en relación a los principios o criterios supletorios señala este autor que los principios generles del derecho han sido "un motivo excelente para que los filósofos del Derecho den rienda suelta a su fantasía, si bien han olvidado, que si el orden jurídico descansa en el principio de la soberanía del pueblo, los principios generales del derecho no pueden ser sino los que el pueblo puso en la base de su orden jurídico, quiere decir, son los principios de la democracia del pueblo para el pueblo"' (14).

Por el contrario, el maestro Plá Rodríguez define a los principios del Derecho del Trabajo asignándoles un carácter polivalente:

"Líneas directrices que informan algunas normas e inspiran directa e indirectamente una serie de soluciones por lo que pueden servir para promover y encausar la aprobación de nuevas normas, orientar la interpreta-

(13) Ibidem. p. 251.

(14) De la Cueva, Mario. El Nuevo Derecho Mexicano del Trabajo. Cuarta Edición. México, Editorial Porrúa, 1977. p. 137. 
ción de las existentes y resolver los casos no previstos" (15).

Destaca el tratadista uruguayo tres elementos fundamentales en los principios generales:

“a) Son enunciados básicos que contemplan, abarcan, comprenden una serie indefinida de situaciones. Un principio es algo más general que una norma porque sirve para inspirarla, para entenderla, para suplirla. Y cumple esa misión respecto de un número indeterminado de normas.

Se ha dicho que constituye un cauce general del ordenamiento, un sentido de la legislación, una orientación recurrente en ella, que se trasluce en una pluralidad de disposiciones. De ahí que se hable de principios básicos o fundamentales, porque sirven de cimiento a toda la estructura jurídico-normativa laboral.

b) Por ser propios del Derecho del Trabajo son distintos de los que existen en otras ramas del Derecho. Sirven para justificar su autonomía y su peculiaridad. (...).

c) Todos los principios deben tener alguna conexión, hilación o armonía entre sí, ya que en su totalidad perfilan la fisonomía característica de una rama autónoma del Derecho que debe tener su unidad y su cohesión internas.

Cada principio constituye una manera de armonizar las normas sirviendo para relacionarlas entre sí y evitando que el sistema se transforme en una serie de fragmentos inconexos. Pero la vinculación entre los distintos principios contribuye más eficazmente todavía a la sistematización del conjunto y a diseñar la peculiar individualidad de cada rama del Derecho" (16).

(15) Plá Rodríguez, Américo. Los Principios del Derecho del Trabajo. Segunda Edición. Buenos Aires, Ediciones Depalma, 1978. p. 9.

(16) Ibidem. p. 10. 
Vázquez Vialard confiere a los principios generales del Derecho el carácter de directivas al Juez para solucionar los conflictos en los casos de oscuridad de la norma aplicable, pero también como directiva hacia el Legislador mismo a fin de ajustar el ordenamiento que no puede sólo responder a su voluntad: "los principios no se agotan en aquellos que han sido acogidos por la ley y constituyen como la malla de la estructura jurídica; hay también otros de derecho natural que la ley puede no haberlos sancionado positivamente, pero que aún considerándolos como derecho extra-legal (extrapositivo) constituyen el fundamento último y primordial del orden jurídico, según la naturaleza de las personas y de las cosas, sobre cuya trama básica, se construye el orden positivo" (17).

\section{Principios Generales o Reglas de Interpretación}

Carlos Blancas privilegia el rol interpretativo de los principios del Derecho del Trabajo:

"El Derecho Laboral no se aparta o deja de lado los clásicos métodos de interpretación del derecho, a saber, los llamados literal o gramatical, lógico, histórico y sistemático, que tienen plena validez dentro de su ámbito, pero la función de tales métodos es complementada con principios o reglas propias de interpretación que unidas a los citados métodos deben contribuir a la mejor comprensión de las normas del Derecho del Trabajo" (18).

A continuación trata este autor los principios de derecho del trabajo que considera ha recogido la Constitución de 1979, esto es principio de irrenunciabilidad, principio protector o pro operario que se concreta en las reglas (o apotegmas jurídicos) de indubio pro operario; norma más favorable; y condición más beneficiosa.

(17) Vázquez Vialard. Tratado del Derecho del Trabajo. Buenos Aires, Editorial Astrea, 1982. pp. 127-128.

(18) Blancas Bustamante, Carlos. La Constitución de 1979 y el Derecho del Trabajo. En "Derecho". Revista de la Pontificia Universidad Católica del Perú. No 36. Lima. Diciembre 1982.p. 27. 
Asimismo, el principio de igualdad de trato y principio de retroactividad benigna. Omite, sin embargo, el principio de continuidad de la relación laboral que consagra el artículo $48^{\circ}$ de la Ley de Leyes.

Creemos que la posición de Blancas tiende a limitar el carácter de estos principios a meras reglas de interpretación del Derecho Laboral. Por el contrario, creemos que corresponden a verdaderos principios, vale decir, que no actúan únicamente como meros orientadores de la labor interpretativa sino como lineamientos directrices que informan e inspiran el ordenamiento laboral en cuanto expresan convicciones sociales que sirven como fundamento del ordenamiento jurídico no sólo actual sino futuro y que reflejan un consenso actual susceptible de evolución y desarrollo.

\section{Principio Protector}

Se ha considerado que el principio protector surge del artículo $57^{\circ}$ de la Constitución, en cuanto señala que "en la interpretación o duda sobre el alcance y contenido de cualquier disposición en materia de trabajo, se está a lo que es más favorable al trabajador'.

No obstante, esta disposición parece acoger uno solo de los conceptos que involucra el principio protector o pro operario, esto es, el conocido como indubio pro operario. Empero, en rigor, el principio protector incluye también la regla de la aplicación de la norma más favorable y la regla de la condición más beneficiosa. Analizaremos brevemente el principio protector y la regla de la norma mas favorable.

Uno de los elementos distintivos del Derecho del Trabajo es el de la subordinación en que se encuentra el trabajador frente a su empleador, que se traduce en tres distintos niveles: técnico, en cuanto es el patrono quien determina las labores y su forma de realización; económico, ya que es el trabajador quien depende para subsistir de la remuneración que se le abone; y jurídica, en cuanto el patrono goza de la prerrogativa de disponer de la capacidad laboral del trabajador durante el íntegro de la jornada. A su vez, esta subordinación implica una sujeción del trabajador a determinadas 
facultades que el principal puede ejercer como consecuencia de la relación laboral: facultad directriz, esto es, la de dirigir el centro de trabajo e impartir disposiciones sobre el desenvolvimiento de la actividad laboral; facultad normativa, que reconoce al principal la prerrogativa de establecer reglas de obligatorio cumplimiento en el centro de trabajo; y facultad disciplinaria, conforme a la cual el empleador puede imponer medidas correctivas al trabajador que incurra en inconductas en el centro de trabajo.

De la constatación de esta desigualdad intrínseca en la relación laboral, surge como contrapeso el principio protector, ya que en el Derecho del Trabajo, a diferencia del Derecho Civil, se parte de la premisa que las partes no son iguales entre sí sino que, por el contrario, se desenvuelven en planos de desigualdad. Por cierto, esta desigualdad no sólo se da en el campo de la relación laboral, actuante y materializada, sino que corresponde a la misma existencia del Derecho del Trabajo como disciplina especializada. Como señala Plá:

"Históricamente el Derecho del Trabajo surgió como consecuencia de que la libertad de contratación entre personas con desigual poder y resistencia económica conducía a distintas formas de explotación. Incluso, las más abusivas e inicuas.

El Legislador no pudo mantener más la ficción de una igualdad existente entre las partes del contrato de trabajo y tendió a compensar esa desigualdad económica desfavorable al trabajador con una protección jurídica favorable al trabajador" (19).

De lo expuesto surge, conforme señala Plá, que no estamos ante "un método especial de interpretación, sino un principio que inspira todas las normas del Derecho y que debe ser tenido en cuenta en su aplicación. . este principio preside la actuación en cada una de las fuentes" (20).

\footnotetext{
(19) Ob. cit. p. 25

(20) Ob. cit. p. 34
} 
Con lo expuesto baste para reiterar que el principio protector engloba tres reglas de las cuales, analizaremos únicamente las reglas de la norma más favorable y de la condición más beneficiosa, que son las que interesan para los efectos del presente trabajo.

\section{Regla de la norma más favorable}

Esta regla, o apotegma, encierra dos sentidos posibles: el primero, "no de la existencia de varias normas aplicables a una relación única, sino de la realidad de una sola norma para una determinada relación, pero en la que se dan varios sentidos" (21). En tál supuesto debe aplicarse la norma en aquel sentido que resulte mas favorable al trabajador. En rigor, en este aspecto, el principio de norma más favorable resulta muy próximo al principio de indubio pro operario, que es el que más nítidamente consagra nuestra Constitución.

En sentido propio, Alonso García señala que esta regla resulta de aplicación cuando existen varias normas susceptibles de ser aplicadas una misma situación jurídica:

"En postura jurídicamente pura, tal supuesto no debiera plantearse, ya que por un lado, se trata de un caso que excede los puros límites interpretativos $\mathrm{y}$, por otro, el principio de jerarquía de las fuentes ... intimamente conectado al de la seguridad jurídica- debiera imponerse, sin lugar a dudas, dando resuelto el problema en el sentido de que entre normas de distinto rango jerárquico, habría que estimar aplicable la de carácter superior y, entre las de rango jerárquico igual, habria de hacerse que prevaleciera la más recientemente promulgada" (22).

La peculiaridad del principio de la norma más favorable implicaría deducir los siguientes criterios, según precisa el profesor español:

(21) Alonso García, Manuel. Ob. cit. p. 253.

(22) Ibidem. pp. 253-254. 
“a) Respeto en todo caso y de modo total y absoluto de los mínimos de derecho necesario que, en cuanto a tales, son inderogables e indisponibles, ni por norma ni por la voluntad de las partes, cediendo, por tanto, y ante los mismos cualquier status regulador que, en su conjunto pudiera estimarse más favorable.

b) Entre normas estatales, de igual o distinto rango jerárquico, prevalecerá aquella -incluso de rango inferior- más favorable para el trabajador.

$$
(\therefore)
$$

e) La determinación de lo que se entienda por más favorable al trabajador obliga a tener en cuenta el conjunto de las normas comparables, o en conflicto, habiendo de decantarse la decisión a adoptar en función del conjunto, cuya apreciación, por lo que respecta a los conceptos cuantificables, se resuelve con la aplicación de un criterio matemático consistente en proceder a una valoración o cómputo anual" (23).

Sobre este particular Vázquez Vialard expresa lo siguiente:

"De conformidad con la aplicación práctica del derecho protectorio que se expresa en esa regla, no opera en el caso el criterio de aplicación de las normas según el orden de jerarquía de sus fuentes. Al efecto, se produce una cierta fractura, de manera tal que, salvo que la comparación (para optar) se realice con disposiciones de orden público general (utilizamos esta expresión para diferenciarlo del llamado orden público laboral) se aplica la más favorable al trabajador, aunque se trate de un uso o costumbre, así como también una que ha sido modificada por otra en cuanto no exista una abrogación expresa o tácita. . . (no) hay laguna legal, sino que, por el contrario hay dos normas, cualquiera que sea su fuente, con aptitud para ser aplica-

(23) Ibidem. pp. 254-255. 
das, por lo cual una de ellas (la más favorable al trabajador) desplaza a la otra. . . Aqui el Juez no debe discurrir si la ley es aplicable o no, pues la solución legal desplazó una norma (que de ese modo perdió su aptitud como tal, aunque no por ello haya sido abrogada por otra que se aplica)" (24).

La comparación de dos normas para determinar si una es más favorable que la otra, ofrece no pocas dificultades. Frente a ello se han utilizado diferentes criterios ya que cabe considerar si las normas deben ser comparadas en su conjunto o si puede tomarse de cada norma aquella parte que sea más favorable al trabajador. A la comparación en su conjunto la doctrina la llama de la inescindibilidad o del conglobamento. A la segunda, esto es, aquella que admite la comparación parcial se le conoce como la teoría de la acumulación. Sus defensores sostienen que la aplicación de una norma puede ser fragmentada a condición de respetar la voluntad de sus autores:

"El conjunto que se toma en cuenta para establecer la comparación es el integrado por las normas referentes al mismo tema, que no puede disociarse sin mengua de su armonía interior" (25).

Conviene dejar establecido que tanto la ley laboral argentina como la española y uruguaya contienen disposiciones expresas que positivizan el principio aludido. No es ese, sin embargo, el caso de la legislación laboral peruana, vale decir, no existe disposición legal que expresamente haya contemplado ese principio general positivándolo. No obstante ello, no es posible negar su existencia como principio general de derecho en nuestra legislación que ha tenido aplicaciones concretas en determinados casos. Verbigracia, en el Decreto Supremo de 28 de agosto de 1952 que estableció reglas relativas a los casos de empleados que tengan derecho a una bonificación por tiempo de servicios semejante a la que había sido recientemente establecida por la Ley 11725 :

(24) Ob.cit.pp. 200-201.

(25) Pla Rodriguez. Ob. cit. p. 60. 
“a) Si el tiempo de servicios exigido (por convenio) para obtener el beneficio particular fuere menor que el señalado por la citada ley, se continuará pagando hasta que el empleado cumpla treinta años de servicios y posteriormente se pagará el beneficio cuyo importe sea más alto, excluyéndose el otro.

b) Cuando se hubiere establecido el requisito de tener más de treinta años de servicios para obtener el beneficio particular se pagará la bonificación ordenada por la ley hasta cumplir el tiempo exigido para gozar del antedicho beneficio, abonándose a partir de ese momento sólo el beneficio más alto.

c) Si el tiempo de servicios exigido para conseguir el beneficio particular fuere igual al fijado por la ley, se pagará el beneficio de importe mayor".

Si bien se está aludiendo al caso de convenios colectivos que pudieran haber establecido mejores beneficios que la ley, es claro que el inciso c) está optando por el principio de la norma más favorable, en este caso por comparación entre un dispositivo de carácter legal y otro de origen convencional, aunque paralelamente se aplica también la regla de la condición más beneficiosa (inciso a).

\section{Regla de la Condición más Beneficiosa}

La importancia de esta regla es innegable en el ámbito laboral contemporáneo, $\mathrm{y}$ ha merecido, inclusive, plasmación en el orden internacional. En efecto, establece el apartado 8 del artículo $19^{\circ}$ de la Constitución de la O.I.T.: "en ningún caso podrá considerarse que la adopción de un convenio o de una recomendación por la Conferencia, o la ratificación de un convenio por cualquier miembro, menoscabará cualquier ley, sentencia, costumbre o acuerdo que garantice a los trabajadores condiciones más favorables que las que figuran en el convenio o en la recomendación". En ese orden de ideas Plá sostiene que esta regla "supone la existencia de una situación concreta anteriormente reconocida y determina que ella debe ser respetada en la medida que sea más favorable al trabajador que la norma que ha de aplicarse", y agrega que el objeto de cada norma es mejorar mas no empeorar la situación del trabajador "ya que si el trabajador en algún aspecto disfruta de 
un nivel de protección superior al que quiere brindarle la norma, ésta resulta inoperante. No roza la situación del trabajador" (26).

Por cierto, se admiten casos de excepción cuando la ley expresamente establezca límites máximos que no puedan ser superados, o que se contraponga otro principio al de la norma mas favorable, por ejemplo, el de la razonabilidad. A modo de ejemplo, ese sería el caso de determinados trabajadores que por coyunturas especiales han obtenido reconocimiento legal para ciertos beneficios que resultan lesivos, para la sociedad en su conjunto, o para la mayoría de los trabajadores que no pueden obtenerlos, siquiera, con similar magnitud. En tal caso, creemos que la nueva ley podría suprimir tales beneficios, que por su naturaleza, corresponden propiamente a privilegios. Dicho en otros términos, creemos que en la medida que, en un ordenamiento democrático, la ley expresa el consenso emanado de un Parlamento, que a su vez refleja el mapa político de una colectividad, y puede por tanto -en expresión de ese consenso político- suprimir un beneficio reconocido por otra disposición legal, siempre que ello así sea expresamente legislado. Cuestión más ardua es aquella que busca determinar si la ley puede suprimir determinados beneficios reconocidos por convenio colectivo, cuando estos lesionan los intereses de la sociedad. Pongamos por caso el de trabajadores de la actividad petrolera que obtienen beneficios de enorme significación que, para ser financiados, hacen indispensable una elevación general del precio de los combustibles. Si se admite que la ley puede dejar sin efecto un convenio colectivo de tal naturaleza, estaríamos, paralelamente, limitando seriamente la capacidad negocial de las partes, vale decir, que la autonomía y el rol protagónico que las partes tienen en la negociación colectiva, se admitiría en tanto y en cuanto ésta no moleste al Estado. Por el contrario, negar la posibilidad de intervención del Estado podría implicar la salvaguarda de privilegios no sólo irritantes sino lesivos al conjunto social.

Al margen de estas consideraciones, es claro que la regla de la condición más beneficiosa reconoce, en favor de aquellos trabajadores que ya gozan de determinados beneficios, lo que se conoce

(26) Ibidem. pp. 61 y 63. 
como derechos adquiridos, a fin de evitar aquello que pudiera significar una reducción de éstos como resultado de una nueva norma que no recoja tales beneficios con la misma amplitud. Para Alonso García la aplicación práctica del principio de condición más beneficiosa supone, pues, dos consecuencias:

"Cuando se dicta una norma de carácter general aplicable a todo un conjunto de situaciones laborales, éstas quedan modificadas en sus condiciones anteriores en cuanto no sean, para el trabajador que venía ya prestando sus servicios, más beneficiosas que las nuevamente establecidas.

"La nueva regulación habrá de respetar -salvo que contuviera afirmación expresa en contra o no hiciera salvedad ninguna respecto de la pervivencia de condiciones precedentes- como situaciones concretas reconocidas en favor del trabajador o trabajadores interesados, aquellas condiciones que resulten más beneficiosas para éstos que las establecidas para la materia o materias de que se trate -o en su conjunto- por la nueva normación" (27).

(27) Ob. cit. pp. 255-256. 


\section{CAPITULO III}

\section{LA INTER-RELACION ENTRE EL PRINCIPIO DE LA JERARQUIA DE LAS NORMAS Y EL PRINCIPIO PROTECTOR DEL DERECHO LABORAL}

1. Alcance del Título Preliminar. 2. Su inter-relación con principios particulares de Derecho. 3. El Principio General: un derecho vivo, 4. A modo de conclusión.

\section{Alcance del Título Preliminar}

La vocación de universalidad de las normas contenidas en el Título Preliminar no surge de su carácter formal, en cuanto disposiciones con rango de ley, sino en cuanto expresan principios generales de derecho. Dicho en otros términos, si las normas del Título Preliminar sólo tuviesen validez formal, en cuanto leyes contenidas en el ordenamiento positivo, carecerían de verdadera vocación de generalidad y no tendrian por objeto estructurar $\mathrm{y}$ dar coherencia a nuestro ordenamiento legal, ya que podrian ser modificadas por cualquier otra disposición legal. Si bien formalmente ello es factible, es evidente que el resto del derecho se subordina, en lo esencial, a las disposiciones contenidas en el Título Preliminar, en razón que positiviza principios generales de Derecho.

Hemos indicado en la Introducción que las disposiciones del Título Preliminar se aplicarían a todas las ramas del derecho. Sin embargo, desde la perspectiva enunciada, esta afirmación tendría que ser morigerada para señalar que es posible percibir entre las distintas normas del Título Preliminar, diversos grados en el nivel de generalidad de los principios generales de derecho que recogen. Como ha señalado Rubio, al graduar la forma como los principios generales informan al derecho, existirian cuatro niveles: el primero, corresponde a principios ideológicos de una sociedad o de una época determinada que tienen validez en diversos campos de la 
vida (la libertad, la igualdad, la justicia y otros similares) advirtiendo que no se trata de valores universales ya que su amplitud o limitación dependerá de su validez ideológica; un segundo nivel de principios propios del Derecho, válidos para todos los derechos establecidos o cuanto menos la generalidad de ellos y de naturaleza técnica (no contradicción del legislador, la ley especial prima sobre la general, etc.) o de carácter valorativo (primer derecho mejor derecho); un tercer grupo de principios, que rige a un derecho (nacional) determinado y lo caracteriza frente a otros; por último, un cuarto grupo de principios que informan diversos aspectos parciales de un sistema jurídico determinado (en nuestro derecho constitucional, la forma republicana de Estado, etc.) (28).

En ese orden de ideas, varias de las disposiciones contenidas en el Título Preliminar, corresponderían a principios generales de derecho de segundo nivel, conforme a la graduación expuesta, y de ahí su vocación de generalidad a las demás ramas del Derecho, antes que como resultado de su validez formal en el ordenamiento positivo. Sin embargo, este mismo hecho determina que a los principios generales que recoge el Título Preliminar puedan ser contrapuestos otros principios de derecho que resulten de aplicación más especifica a una rama determinada de la ciencia jurídica.

\section{Su Inter-relación con principios particulares del Derecho}

Una disposición tan genérica y presuntamente tan universal como la contenida en el artículo $1^{\circ}$ del Título Preliminar, en cuanto consagra que "la ley se deroga sólo por otra ley" y que recoge también el artículo $87^{\circ}$ de la Constitución, sólo tendría un valor relativo en el campo del Derecho Laboral, como principio general de Derecho, susceptible de ser subordinado a otro que limitaría su eficacia. En efecto, en el Derecho Laboral, será el principio protector (norma más favorable) el que prevalezca para la aplicación de la respectiva disposición, inclusive por encima de la respectiva jerarquía de normas. Si bien, no podría afirmarse que una ley pueda ser "derogada" por un Decreto Supremo o una costumbre, es claro que en el Derecho Laboral dejaría de aplicarse si es que la

(28) Ob. cit. p. 150. 
segunda disposición -no obstante ser de menor jerarquía o no ser propiamente una fuente- contiene un beneficio más favorable.

En rigor, en esta rama del Derecho se ha optado por la prevalencia del principio protector, en su regla de norma más favorable, frente al principio de la jerarquía de las normas, expresado tanto en la regla del artículo $1^{\circ}$ del Título Preliminar, como en el artículo $87^{\circ}$ de la Constitución. Ello implica convenir que el primero constituye un principio de Derecho que refleja, en materia laboral, nuestras convicciones jurídicas fundamentales, conforme a las cuales los derechos laborales son esencialmente progresivos en el reconocimiento de beneficios al trabajador, con prescindencia al basamento legal en que esta progresión pueda estar recogida. Al optar por ese principio del Derecho Laboral no estamos ante un problema de suplencia o laguna, que por el contrario no se presenta, toda vez que existe la norma del artículo $1^{\circ}$ del Título Preliminar. Sin embargo, el intérprete en el Derecho del Trabajo no aplicará esa norma del Título Preliminar porque sólo le reconocerá valor como principio general susceptible de ser contrapuesto a un principio particular. Por ende se resistirá a admitir que "la ley sólo se deroga por otra ley" y privilegiará un dispositivo de inferior jerarquía - no "derogando" sino haciendo inoperativo el de mayor jerarquía- cuando aquél recoja un mayor beneficio para el trabajador, aun cuando, formalmente, ello carecería de eficacia jurídica por ir más allá de los preceptos contenidos en una norma de mayor nivel. Nuestra convicción socialmente aceptada determina que ello sea así porque otro principio general, es decir un sustento interno que informa nuestro Derecho Laboral -el principio protector- le da su verdadero sentido a ese otro principio general de jerarquía de las normas que recogen la Constitución y el Título Preliminar.

\section{El Principio General: un derecho vivo}

No podría afirmarse válidamente que antes de la dación de la primera ley de estabilidad laboral en el Perú, en el año 1970 (Decreto Ley 18471) correspondía a un principio de nuestro Derecho del Trabajo la continuidad del vínculo laboral. Sin embargo, a partir de esa norma, y otras posteriores, se genera un proceso de retroalimentación que interactúa tanto en la conciencia jurídica de 
nuestra colectividad como en nuestro ordenamiento legal y que concluye positivizando un principio general de derecho laboral -la continuidad de la relación de trabajo-que se plasma en el artículo $48^{\circ}$ de la Constitución: "El Estado reconoce el derecho de estabilidad en el trabajo. El trabajador sólo puede ser despedido por causa justa, señalada en la ley y debidamente comprobada". En el presente caso, es claro que, contra la tesis de Betti que ya hemos comentado, no medió una evolución jurisprudencial sino la súbita aparición de un nuevo derecho en el Decreto Ley 18471 , respecto del cual ni siquiera existían en ese entonces precedentes legislativos en otros ordenamientos positivos. Sin embargo, con el transcurso del tiempo el reconocimiento de ese derecho caló en nuestra convicción social hasta elevarlo a la categoría de principio de nuestro ordenamiento laboral, hoy consagrado a nivel constitucional, y que determina que en la conciencia jurídica del Perú no sería socialmente admisible que el despido sin justa causa no conlleve alguna forma de sanción. Por ello, la protección contra el despido arbitrario es una constante que informa no sólo nuestra legislación y jurisprudencia recientes sino nuestra forma de raciocinio jurídico frente al problema, más allá del enunciado formal que contiene la norma constitucional.

\section{A modo de conclusión}

Existe, pues, una interrelación dinámica entre algunos de los principios generales que inspiran determinadas normas del Título Preliminar, y ciertos principios que informan el Derecho del Trabajo, verbigracia, entre el principio general de la jerarquía de las normas frente al principio de la norma más favorable.

Es pues en este conflicto de valores inmersos en ambos principios, que la convicción jurídica imperante en la ideología de nuestra colectividad efectúa una opción privilegiando el principio propio del Derecho Laboral, y reinterpretando el alcance de esa norma del Título Preliminar. Así, le reconoce al artículo $1^{\circ}$ del Título Preliminar, un carácter de principio general antes que un valor formal a ultranza.

Mediante esta re-creación del Derecho, se expresan pues los valores que nuestra sociedad considera más rescatables, dándole 
así su verdadera dimensión a los principios generales del Derecho como expresión viva de las convicciones imperantes en nuestra colectividad. 